\title{
12. ROLE OF QUALITY AND EQUITY IN EDUCATION
}

\section{ABSTRACT}

Education yields economic and social benefits for individuals and countries. The acknowledgement of these benefits, with economic globalization, has heightened interest in international comparisons on education. Current completion rates of upper secondary and tertiary education differ markedly among countries, as do changes in completion rates over the last three decades. Performances of 15-year-olds in reading, mathematics, science and problem-solving also vary substantially among countries. In all countries, there is a positive relationship between students' social backgrounds and their educational performances, revealing an important level of inequity in education systems. The strength of this relationship varies across countries, however, with some high-quality systems also being high-equity. Evidently, quality and equity can be achieved together. Countries differ in the extent of variation in average performance between schools. In some countries there is very little difference. In others, there are substantial differences by design with students streamed by performance level into different kinds of schools to minimize variation within schools and maximize variation between schools. In others, differences between schools arise less deliberately. Where between-school variation is large, much of it can be explained in many countries in terms of differences in the students' social backgrounds. Socially disadvantaged students suffer an additional disadvantage if they are predominantly in the company of other disadvantaged students. Socially advantaged students, on the other hand, do not gain much from restricted company with other advantaged students, making the case for heterogeneity strong. On almost all measures, the United States' school system compares unfavorably with others, yet its economy remains the world leader that others seek to match. The lessons for others do not lie in United States' schools but rather in its higher education system, particularly its graduate schools; its labor market's emphasis on skills, not qualifications; its entrepreneurial tradition; and its capacity to attract the best from elsewhere. 


\section{INTRODUCTION}

Economic globalization and recognition of the importance of education for economic development have heightened interest in international comparisons of the performance of national education systems. Intemational comparative data on education systems are published annually by the Organization for Economic Co-operation and Development (OECD) in Education at a Glance (OECD, 2006a). The breadth of these data has been extended with the development of OECD's Program for International Student Assessment (PISA), which measures the performance of 15-year-olds students on a three-year cycle that began in 2000 .

\section{ECONOMIC BENEFITS OF EDUCATION}

OECD work makes clear the extent to which higher levels of education pay off for countries and individuals. Studies of the benefits for countries focus on the relationship between the stock of human capital and either the level or the rate of growth of the gross domestic product (GDP). The stock of human capital is estimated as the average number of years of formal education of working-age persons in a population. The general conclusion advanced by the OECD is that an increase of one year in the average level of education of the working-age population raises GDP by 3 percent to 6 percent and increases the growth rate by approximately 1 percent. There is some evidence that the payoff diminishes as the average level of education rises above levels that many OECD countries already exceed (OECD 2006a, p. 157).

Similar effects appear when the quality, rather than the quantity, of human capital is measured. Using literacy levels in the adult population as the indicator of human capital instead of the number of years of formal education, Coulomb and colleagues conclude that a country able to attain literacy scores 1 percent higher than the intemational average will achieve levels of labor productivity and GDP per capita that are 2.5 percent and 1.5 percent higher, respectively, than those at the average (cited in OECD, 2006a, p. 157).

The benefits of higher levels of education for individuals lie in higher employment rates (OECD, 2006a, pp. 112-113), lower unemployment rates (OECD, 2006a, pp. 114-115) and higher average earnings (OECD, 2006a, pp. 135-136). A more complete analysis of the financial benefits, taking account not only of differences in pre-tax income but also of the additional costs of remaining in education and higher rates of income tax on higher earnings, shows relatively high internal rates of return. For example, the internal rates of return for an individual completing a university degree, compared with completing only secondary education, are 14 percent for males and 13 percent for females in the United States and 17 percent for males and 20 percent for females in the United Kingdom. The rates are somewhat lower where salary differentials are less marked and income tax more progressive, but they are not trivial. In Sweden, rates of return are 9 percent for males and 8 percent for females (OECD, 2006a, p. 150).

Despite the growth in the proportion of the population completing tertiary education, there is no evidence that, over the past $10-15$ years, the benefits for individuals of completing tertiary education have diminished (OECD, 2006a, pp. 116-117, 118-119, 139-140).

\section{INTERNATIONAL DIFFERENCES IN THE STOCK OF HUMAN CAPITAL}

\section{Differences in Educational Attainment}

There are marked differences among countries in the stock of human capital, as measured by the number of years of formal education completed. There are no internationally comparable data on trends in completion rates for different levels of education, but a picture for past decades can be obtained from the percentages of the population in different age brackets that have attained particular levels.

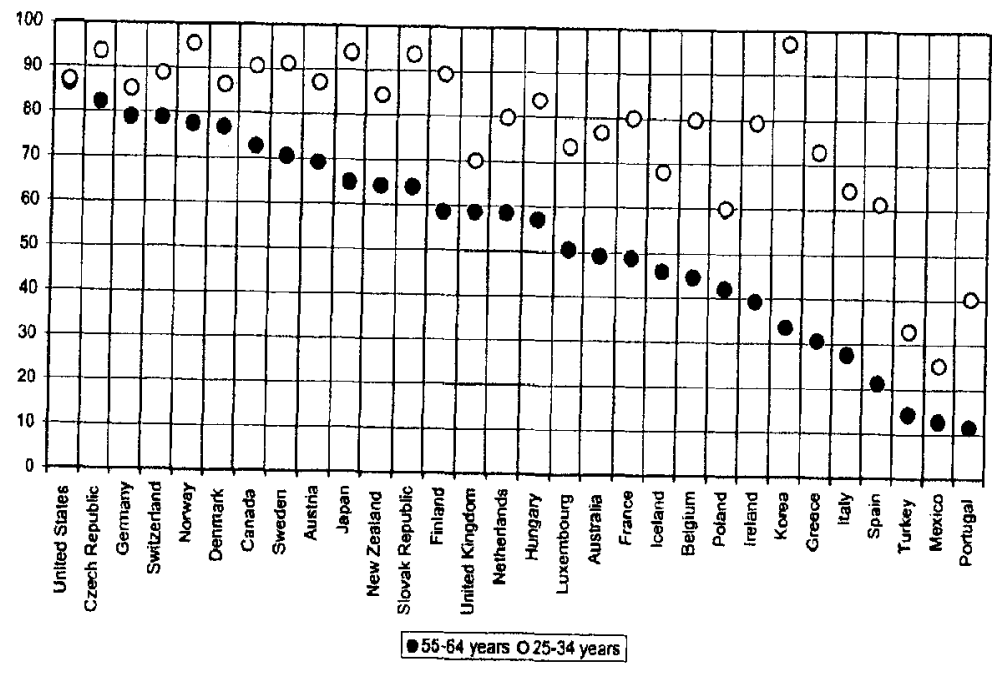

Figure 1. Percentage of age-groups having completed upper secondary education. 
The percentages of 55-64 year-olds who have attained upper secondary education indicate completion rates 37-46 years ago. The picture is only approximate because some will have attained this level as adults, long after having left initial education, and also because some of the population will not have survived to this age. The percentages of 25-34 year-olds indicate the completion rates $7-16$ years ago. Comparisons for OECD countries are shown in Figure 1 (OECD, 2006a, p. 38).

Among 25-34 year-olds, 17 of the 30 OECD countries have completion rates of 80 percent or higher. The United States is ranked first among 5564 year-olds but only 11 th among 25-34 year-olds. The Republic of South Korea, on the other hand, started from a low base, ranking 24 th among 5564 year-olds but has developed quickly to rank first among 25-34 yearolds. Over the same period, Japan rose from 10 th to third. Meanwhile Canada held its ranking at seventh.

Trend data on completion of tertiary education (type A and type B) can be estimated in the same manner. The rates are for the completion of either a tertiary type A or a tertiary type B qualification. Tertiary-type A programs are largely theory-based and are designed to provide sufficient qualifications for entry to advanced research programs and professions with high skill requirements; tertiary-type B programs are typically shorter and focus on practical, technical or occupational skills for direct entry into the labor market, although some theoretical foundations may be covered

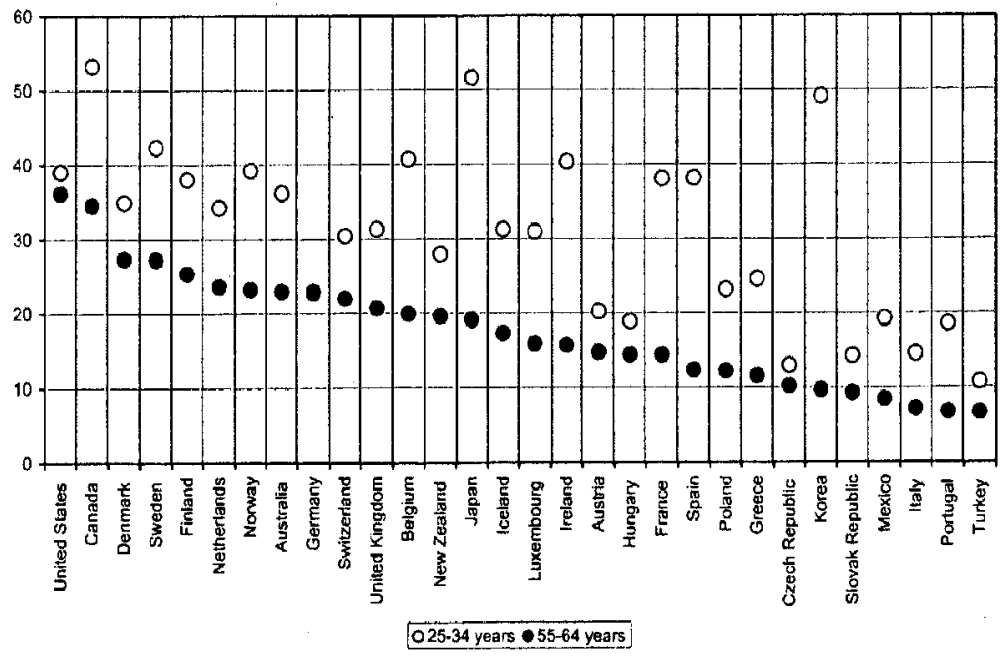

Figure 2. Percentage of age-groups having completed tertiary education.
(OECD, 2006b). The comparisons for OECD countries are shown in Figure 2 (OECD, 2006a, p. 39).

The developments in the Republic of South Korea, shown in Figures 1 and 2 are remarkable. In the mid-1960s, South Korea had a GDP per capita equivalent to that of Afghanistan and behind all the countries of Latin America. South Korea is now a member of the OECD, with a GDP per capita just below the top two-thirds of the members (Maddison, 2001). Education reform and a deep national commitment to education and skill development are recognized as key drivers of this remarkable economic growth.

\section{Differences in Educational Quality}

There are also marked differences among countries in the quality of the stock of human capital, revealed by results in PISA (for which details are available at http://www.pisa.oecd.org). PISA provides direct, internationally comparable assessments of the achievements of 15-year-olds, the target population being 15-year-olds in schools of any type and thus excluding 15-year-olds not in school. PISA 2000 assessed students in reading literacy, mathematics and science, with reading literacy as the main domain and mathematics and science as minor domains. In PISA 2003, mathematics was the main domain and reading, science and problem-solving were minor domains. PISA 2006 assessed the three original domains, with science as the main domain. Additional information is obtained through questionnaires completed by students and school principals.

PISA assesses students' capacity to use the knowledge and skills they have acquired, not whether they have learned specific curriculum content. Both open-ended and multiple-choice questions are used. In the PISA 2003 mathematics portion, for example, there were 17 simple multiple-choice items, 11 complex multiple-choice items, and 57 items for which students constructed their response. Sample items, illustrating the content and form of assessment, are provided on the PISA website.

All potential assessment materials are first reviewed in all participating countries for prima facie evidence of cultural bias, with doubtful items being removed prior to an internationally controlled trial in all participating countries. Student performance on the trial material provides empirical evidence on whether tasks work consistently in all countries. Tasks that do not are removed from the pool available for selection for use in the final tests.

The mean performances of countries in reading literacy in PISA 2000 are shown in Figure 3; the line in the middle of the box for each country 
gives the mean performance and the size of a box reflects the precision with which a country's mean is estimated (OECD \& UNESCO, 2003, p. 76). India does not participate in PISA and only Hong Kong-China and Macao-China participate from China.

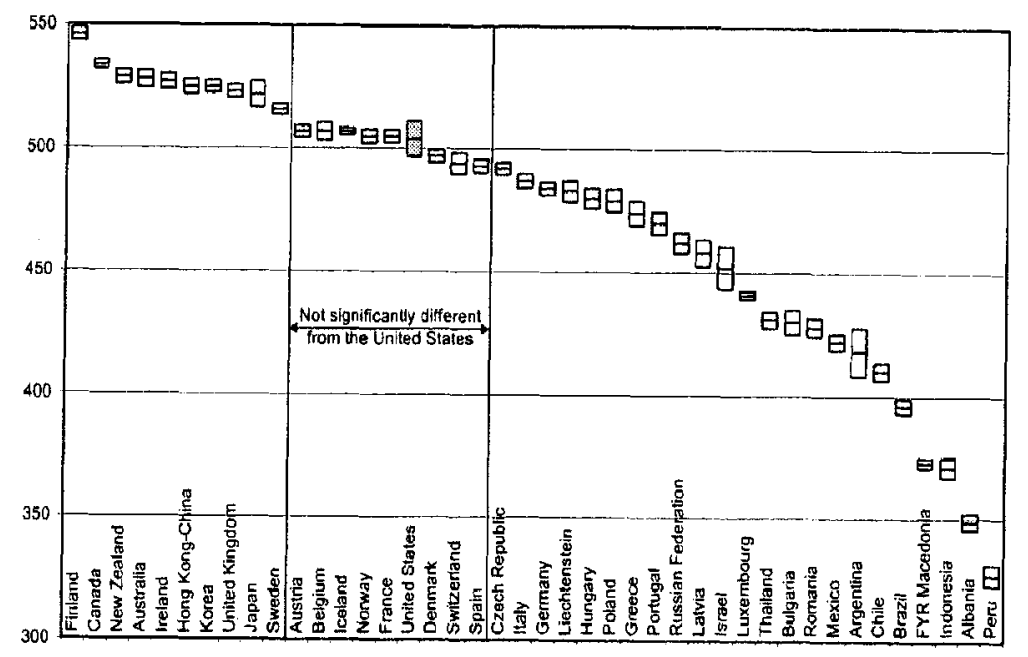

Figure 3. Mean performances of 15-year-olds in reading literacy in PISA 2000.

The results reveal marked variations in performance levels among the 42 participating countries - ranging from Finland, significantly better than all others at the top, to Peru, significantly worse than all others at the bottom. Where the boxes overlap on the vertical dimension, there is no significant difference between the means for the countries. (Further details are given in OECD \& UNESCO, 2003.) The mean for the United States was one of the less precisely estimated means. Better sampling in 2003 produced a more precise United States' estimate (OECD, 2004a).

The United States ranked 16th for reading literacy in PISA 2000 but with a mean not significantly different from those of five countries above it or three below it. It is appropriate, therefore, to say that the United States ranked between 11 th and 19 th or that the United States tied in 11 th place with eight other countries.

More detailed analysis of the distributions of results reveals that the United States has a relatively high proportion of 15 -year-olds performing at a high level on the scale (OECD \& UNESCO, 2003, p. 69). Its mean value is so low among OECD countries because it also has a relatively high proportion of the population performing at a very low level. It is thus only on-average that United States' 15 -year-olds perform at an average level among the other countries in reading literacy.

Comparisons among countries of student performance in mathematics, using the data from PISA 2003 when mathematics was the main assessment domain, are shown in Figure 4.

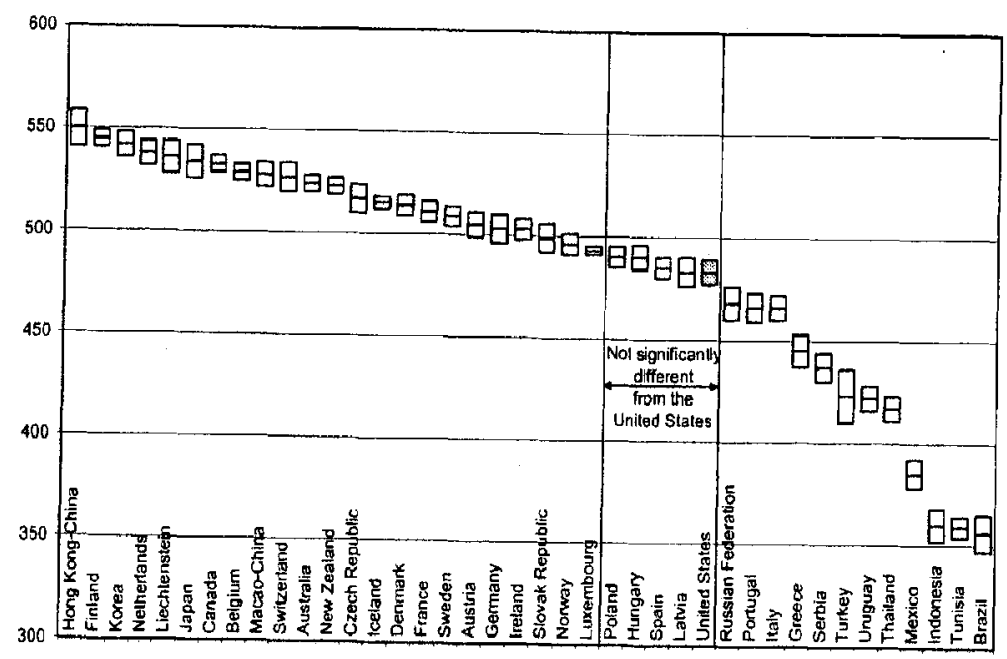

Figure 4. Mean performances of 15-year-olds in mathematics in PISA 2003.

As with reading literacy, the results for mathematics reveal marked variations in performance levels among the participating countries ranging from Hong Kong-China to Brazil. The United States ranked 28th, but its mean is not significantly different from those of Poland, Hungary, Spain and Latvia ranking above it. It is appropriate, therefore, to say that the United States ranked between 24th and 28th or that the United States tied in 24th place with four other countries (OECD, 2004a, p. 92).

Unlike in reading literacy in PISA 2000, the distribution of results in the United States' sample reflects its low average position. The proportion of students performing at the highest level on the scale is correspondingly low (OECD, 2004a, p. 91).

Problem-solving was assessed in PISA 2003 in three types of situations: making decisions under constraints; evaluating and designing systems for a particular situation; and trouble-shooting a malfunctioning device or system based on a set of symptoms. On this performance measure, Korea, Hong Kong-China, Finland and Japan ranked at the top with no significant 
differences among them. The United States ranked between 25 th and 31 st or tied in 25 th place with six other countries (OECD, 2004b, p. 42).

\section{EQUITY IN THE CREATION OF HUMAN CAPITAL}

There are not only differences among countries in the quality of education but also in the equity of their systems. In PISA, the 15-year-olds in the sample complete a questionnaire that collects information on their parents' education and occupation, and cultural artifacts in the home that permits the construction of an index of social background, which ranges from socially disadvantaged to socially advantaged. This scale is comparable across countries. With this measure, the equity of PISA results can be examined in several ways.

\section{Social Gradients}

The correlation between social background and reading literacy in PISA 2000 across the OECD as a whole was relatively high, at around 0.45 , indicating a strong relationship between the two variables. The slope of the regression line that summarizes the relationship is quite steep, indicating that increased social advantage, in general, pays off with considerable increase in educational performance. There are many individual exceptions socially advantaged individuals who do not perform well and students from disadvantaged backgrounds who do perform well.

This result has been long established in research in many individual countries, and it can lead to a counsel of despair. Education systems can seem impotent in the face of such a strong influence of social background on educational achievement. There is other research evidence that provides assurance that schools can make a difference to the life chances of their students. The PISA results also provide a similar encouraging message through comparison of the regressions lines for individual countries.

The results from four countries in Figure 5 with PISA 2000 data show the regression of reading literacy on social background (OECD, 2001, p. 308). The lines for Finland and Canada are significantly less steep than the one for the OECD as a whole. Increased social advantage in these countries is associated with less increase in educational achievement than in the OECD as a whole. Students differ in achievement but not in a way that is substantially related to their social background. In that sense, their educational achievements are more equitable than those in the OECD overall.

The lines for the United States and Germany are significantly steeper than the one for the OECD as a whole. Their results are inequitable in the sense that differences among students in literacy levels reflect a significantly more marked extent than in other countries' differences in the students' social backgrounds.

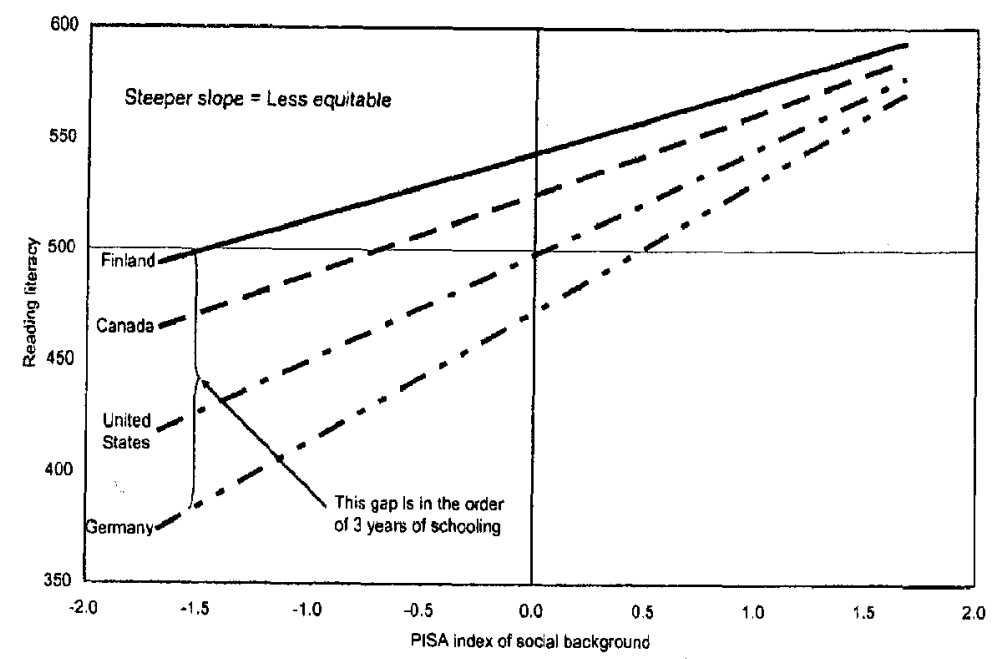

Figure 5. Regression of reading literacy on social background in PISA 2003.

The differences between these regression lines at the left-hand end are substantial. Socially disadvantaged students do much worse in some of these countries. The gap in educational achievement between similarly socially disadvantaged students in Germany and Finland represents around three years of schooling.

More detailed analysis of the German data shows the pattern to be strongly related to the organization of schooling. From age 11, students are separated into vocational and academic schools of various types on the basis of the educational future judged to be most appropriate for them. Students from socially disadvantaged backgrounds generally end up in lowstatus vocational school and achieve poor educational results. Students from socially advantaged backgrounds are directed to high-status academic schools where they achieve high-quality results. The schooling system largely reproduces the existing social arrangements, conferring privilege where it already exists and denying it where it does not.

If regression lines for more countries were added to Figure 5, the pattern would become difficult to discern. It can be seen in Figure 6 in which all countries assessed in PISA 2000 are located using their mean performance 
in reading and the slopes of the lines for their regression of reading performance on social background.

Mean performances of countries in reading literacy are represented on the vertical axis. The equity of results is represented on the horizontal axis as the difference between the regression slope for the OECD as a whole and a country's own slope (OECD \& UNESCO, 2003, pp. 334-335). This places to the left countries where the slope is steeper than in the OECD as a whole (that is, countries in which social background is more substantially related to educational achievement) and to the right, countries where the slope is less steep than that for the OECD as a whole (that is, countries in which social background is less related to educational achievement).

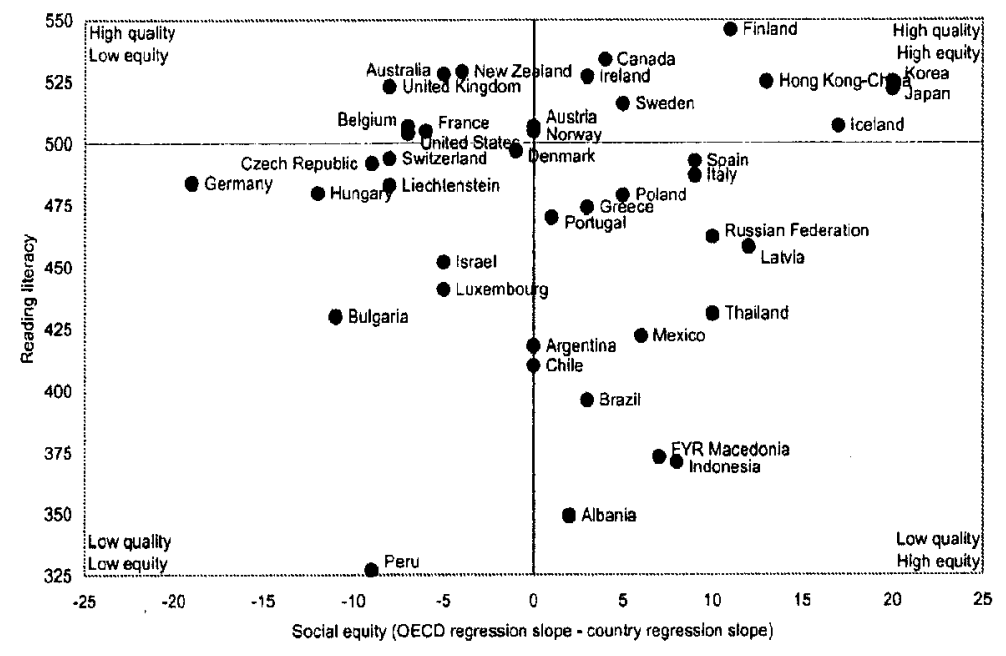

Figure 6. Mean reading literacy versus social equity of results in PISA 2003.

The graph is divided into four quadrants on the basis of the OECD average on the two measures. Countries in the top right are high-quality and high-equity. This shows that it is possible to achieve both together. Korea, Japan, Hong Kong-China, Finland and Canada are among them.

Among countries in the bottom right, there are many "low-quality, highequity" countries where a good proportion of 15-year-olds are not in school. Results may be equitable among those who remain, but the inequity in the system occurs in the early departures of many students before age 15 .

It is clear that some countries ameliorate the impact of differences in social background on educational achievement to a much greater extent than do others. Most importantly, there is no necessary trade-off between quality and equity.

\section{Sources of Variation between Schools}

In Figure 7, the variation in student performance for each country in mathematics in PISA 2003 is divided into a component due to differences among students within schools, shown above the zero line, and a component due to differences between schools, shown below the zero line. In Iceland, Finland and Norway, there is very little variation in scores between schools, so for parents in these countries, choice of school is not very important. Among the countries in which there is a large component of variation between schools, there are some such as Hungary, Belgium and Germany where this is a consequence of policy with students being sorted into schools of different types according to their school performance as early as age 12 . This is intended to minimize variation within schools and maximize differences between schools of different types for which different curricula are then provided.

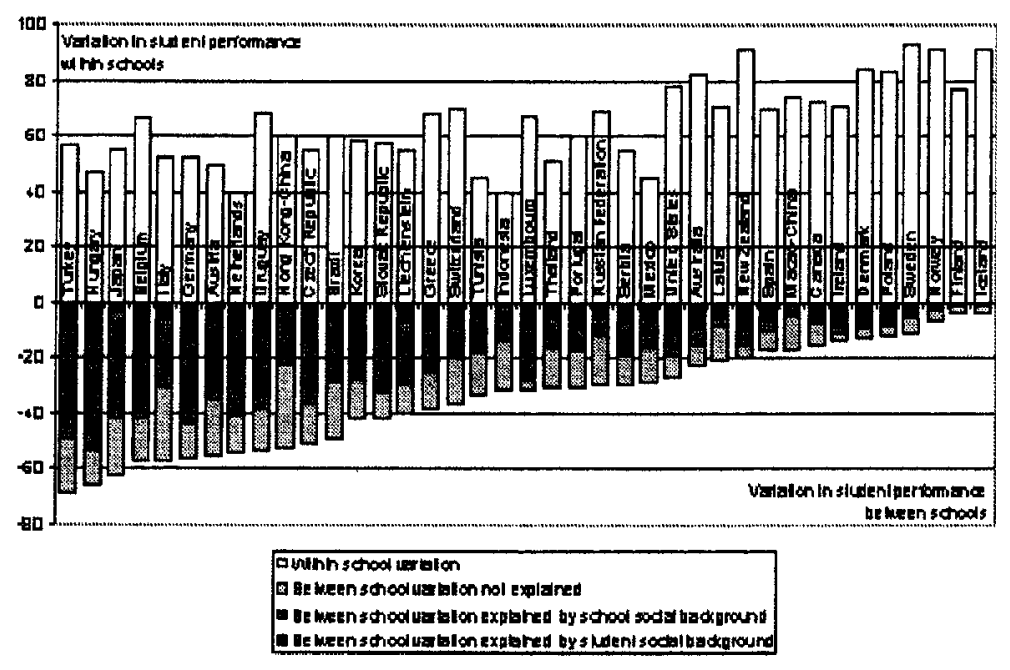

Figure 7. Components of variation in mathematics performance in PISA 2003.

In some other countries, the grouping of students is less deliberate but, nevertheless, results in substantial between-school variation. In Japan, for example, 53 percent of the overall variation is between schools. In Korea, 42 percent is between schools. In the United States, it is 26 percent. 
For Poland in PISA 2000, 63 percent of the variation in reading was between schools, whereas in PISA 2003 in mathematics, it was only 13 percent. This remarkable change was due to a reform in which early streaming of students into schools of different types was abandoned in favor of comprehensive schools for students up to the age at which PISA measures their performance. Poland not only reduced its between-school variation, it was the only country to improve its average performance significantly on all measures used in both PISA 2000 and PISA 2003. It did so largely by raising the achievement levels of its poorer-performing students who, under the reform, were placed in more comprehensive and heterogeneous schools and not isolated in relatively homogeneous schools.

A further way in which to examine equity is to determine the extent to which the variation between schools can be explained in terms of differences in the social backgrounds of the students. This is done in Figure 7, in which the between-school variation is subdivided into three components:

- variation that can be accounted for in terms of the social backgrounds of the individual students in the schools;

- variation that can be accounted for in terms of the average social background of the students in the schools; and

- variation that cannot be accounted for in terms of the social backgrounds of the students.

The first reflects the impact of students' own social backgrounds on their educational outcomes and the second, the impact of the social backgrounds of other students in their schools. In the United States, 70 percent of the variation between-schools can be accounted for in terms of differences in the social background of students between schools; 45 percent by individual social background and 25 percent by the average social background of students in the schools.

Where differences in social background account for a large percentage of the between-school variation, this suggests that the educational arrangements in the country are inequitable. Where much of the account derives from the social background of other students in the school, it suggests that there is a benefit for advantaged students in keeping company with similarly advantaged students but a compounded disadvantage for disadvantaged students keeping company with others like themselves. That suggests an impossible policy conundrum for those who might want different groupings to ameliorate the influence of social background on disadvantaged students, because it implies that reduction in disadvantage for them could only be won with an accompanying reduction in advantage for the advantaged. Additional analyses of the PISA 2000 data for Austria, however, offer a more encouraging conclusion. These analyses suggest, as reported by Schneeweis and Winter-Ebmer (2005, p. 2):

students with lower skills benefit more from being exposed to clever peers, whereas those with higher skills do not seem to be affected much. Social heterogeneity, moreover, has no big adverse effect on academic outcomes. These results imply considerable social gains of reducing stratification in educational settings.

\section{CONNECTING EDUCATIONAL AND ECONOMIC DEVELOPMENT}

Many countries aspire to match the level of economic development achieved in the United States. As the economies of India and China develop, there is much interest in them among more developed countries, including the United States, but for the present, at least, the United States sets the economic performance benchmark.

The European Union (EU) sees the United States as a target, if not a model. When the EU Heads of State met in Lisbon in March 2000, they adopted the goal of the EU becoming the "most competitive and dynamic knowledge-based economy in the world" by 2010 . They did not name the competition but it was clear that, to become number one, they would have to overtake the United States. To achieve this goal, the EU Heads of State declared that there would need to be:

- a radical transformation of the European economy;

- a modernization of its welfare system; and

- a modernization of its education system.

The EU Ministers of Education set three major goals to be achieved as their contribution to meeting the broader goal established in Lisbon (see http://ec.europa.eu/education/policies/2010/et_2010_en.html):

- to improve the quality and effectiveness of EU education and training systems;

- to ensure that they are accessible to all;

- to open up education and training to the wider world.

Given the belief that education is one of the key policy areas through which economic advancement is achieved, an important question in the light of the international comparisons of the performance of education systems is "How does the United States have such a strong economy when its school education is so weak?"

The first possibility is that education does not matter. But there is good evidence that it does, some of it referred to in the opening section of this chapter. The question then becomes, "How does the United States make up 
for the disadvantages of a weak school education system?" There are five possibilities worth considering:

- Economic development depends on high level skills in an elite, not the whole, population.

- The entrepreneurial tradition in the United States, coupled with a labor market that matches skills rather than qualifications to jobs, generates high levels of productivity.

- The United States gained a first-mover advantage by achieving high levels of participation in higher education well before other countries. If that is the case, then the advantage may now be eroding as a growing number of other countries are achieving higher participation rates in tertiary education than the United States, as shown in Figure 2.

- The United States makes up for the deficiencies in its own school education system with a high-quality higher education system, particularly at the graduate level.

- The United States covers the deficiencies in its own education system by recruiting individuals from high-quality systems in other countries.

- The United States makes up for the deficiencies in its education system through extensive, well-focused, job-related continuing education.

There is no strong empirical evidence for which is best among these contending explanations. The explanation is likely to involve a combination.

\section{CONCLUSIONS}

India and China should see the United States as a target knowledge economy to be matched, as the European Union does. They should not look to the United States' school education system as a model, except very selectively and in well-informed ways to find exceptional examples.

School education is the United States is, overall, of average quality in reading and well below average quality in mathematics, science and problem-solving. It is also low-equity in the sense that differences in students' social backgrounds are more strongly related to differences in their educational outcomes than in many other countries, including some that achieve high-quality results as well as high-equity.

The strengths of the United States' education system that other countries would be best advised to emulate lie in its higher education system, particularly in its graduate schools with their emphasis on research and research training. As they match the United States in this respect, some are already competing more effectively with the United States for a share of the world's high-achieving students from other countries' high-quality education systems.
And where should the United States look? Certainly, it needs to use the international comparisons to guide its search abroad for lessons to improve its own school education system. India and China may well be among those that offer valuable lessons.

\section{REFERENCES}

Maddison, A. (2001). The world economy: A millennial perspective. Paris: OECD.

OECD. (2001). Knowledge and skills for life: First results from PISA 2000. Paris: OECD

OECD, \& UNESCO. (2003.) Literacy skills for the world of tomorrow: Further results from PISA 2000. Paris: OECD.

OECD. (2004a), Learning for tomorrow's world: First results from PISA 2003. Paris: OECD.

OECD. (2004b). Problem solving for tomorrow's world: First results from PISA 2003. Paris: OECD. OECD. (2006a). Education at a glance 2006. Paris: OECD.

OECD. (2006b). Glossary to the OECD Education at a glance 2006. Retrieved June 22, 2007, from $\mathrm{http}: / /$ www.oecd.org/edu/eag2006

Schneeweis, N., \& Winter-Ebmer, R. (2005). Peer effects in Austrian schools. Working Paper No. 0502, Department of Economics, Johannes Kepler University of Linz, Austria.

Barry McGaw, Director Melbourne Education Research Institute

University of Melbourne 


\section{University Library}

\section{- M M I N E R VA A gateway to Melbourne's research publications}

Minerva Access is the Institutional Repository of The University of Melbourne

Author/s:

McGaw, B

Title:

Role of quality and equity in education

Date:

2008-01-01

Citation:

McGaw, B. (2008). Role of quality and equity in education. DeHaan, R (Ed.). Venkat Narayan, K (Ed.). Education for Innovation: Implications for India, China and America, (1), pp.249-263. Sense Publishers.

Persistent Link:

http://hdl.handle.net/11343/28495 